\title{
Teacher-student communication ecology as a module of pre-service teachers' education
}

\author{
E.A. Kazantseva ${ }^{1 *}, F . G$. Fatkullina ${ }^{2}$, and E.K. Valiakhmetova ${ }^{3}$ \\ ${ }^{1}$ Ufa State Petroleum Technological University, Ufa, Russia \\ ${ }^{2}$ Bashkir State University, Ufa, Russia \\ ${ }^{3}$ Ufa law institute of the Ministry of Internal Affairs of Russia, Ufa Russia
}

\begin{abstract}
The article deals with the problem of teacher-student communication ecology as a module of pre-service teachers' education. This approach restore the status of fundamental education and science, and the social status of the teacher. The sphere of Russian education is currently under reform: a difficult process that neither people, nor the language they use, can quickly adapt to. The purpose of this paper is to reveal the subject areas that could provide young and pre-service teachers with language tools facilitating communication with students, contributing to more productive communication, and thus providing better learning outcomes. According to the research findings, the key to solving the identified systemic problems in academic discourse is to adjust the balance of the categories of self-respect - respect for the Other, which should be implemented at the stage of personal development. This paper presents general guidelines that can set the direction of subsequent stages of scientific research. According to the research findings, this module should cover such areas as: the norms of academic communication, and academic language, emotional academic literacy, efficient linguistic communication tools.
\end{abstract}

\section{A problem statement}

Communicative ecology (the term was coined by D.L. Altheide [1]) is a concept model aimed at research into relations between social interactions and communication technologies in physical and digital environments and has been in research focus of many scholars $[2 ; 3 ; 4$ etc]. This approach allows to expand ecology as a science from humannature to human-human relationships and pose a question on the urgency of ecological regulation of communicative space including the system of education as one of the most important institutes of socialization. This paradigm of environmental communication can find utility in the structures of cultural and educational space both in practically-applied aspects, and on the ideological level, to restore the status of fundamental education and science, and the social status of the teacher, as well as for the implementation of sociocultural monitoring [5].

\footnotetext{
* Corresponding author: ipcs-profped@yandex.ru
} 
Speaking about the ecology of academic communication, it is necessary to take into account that the sphere of Russian education (both secondary and higher) is currently under reform: a difficult process that neither people, nor the language they use, can quickly adapt to. Besides, all this is happening in a world that is experiencing a sharp turn in its development. An increase in lingua-ecological problems in the Russian academic space is evident and highlighted in the literature $[6 ; 7 ; 8]$, which supports the actuality of the research presented.

Communicative imbalance is currently most acutely felt in the secondary school academic communication space, causing concern with representatives of various sciences: sociologists, psychologists, linguists, and more recently, medics [9; 10]. Research by Russian psychologists confirms that in recent years, the Russian school has indeed undergone dramatic changes affecting all the main discourse participants [11]. The Soviet family-type school went down in history, and what replaced it has deprived the teacher of their usual high social status, lowering them to the category of service personnel. A sharp increase in mental, physical and emotional loads which is further complicated by an increase in the average age of the teaching staff also contribute to the lingua ecological problems in the Russian academic communication space [12;13]. With the spread of distance form of education becoming more and more actual in the modern world these problems may be exacerbated as distance teaching requires students to be highly motivated and able to deal with time efficiently while personal contact with the teacher and other students is limited [14].

Our previous studies $[15,16]$ aimed at communication ecology in academic discourse produced some findings that might be successfully used in practice. The purpose of this paper is to reveal the subject areas that could provide young and pre-service teachers with language tools facilitating communication with students, contributing to more productive communication, and thus providing better learning outcomes.

\subsection{The objective of the work}

The research outline: linguo-ecological perspective of academic discourse; a multi-aspect study of the phenomenon: identification of taxonomic characteristics of academic discourse in the expanded understanding of the term, statistical and probabilistic modeling of emotional and need-based relationships in the process of cognitive activity, development of a method for the assessment of the potential emotionogenic impact of a speech stimulus on the addressee, confirmed by field studies data; a comparative description of the lingua ecological characteristics of academic discourse in the English and Russian academic cultures. The comparative description was performed in two projections - linguisticcultural (including psycholinguistic description) and lingua-ecological (using the tools of cognitive pragmatics).

The research methods include theoretical analysis and synthesis of scientific information on the topic under consideration, generalization of the European experience of academic communication, comparative analysis of communicative ecology in the sphere of education.

To collect empirical data, we applied sociolinguistics and psycholinguistics methods such as a series of surveys and interviews, associative experiment. The data underwent statistical processing and were analyzed using complex methods of emotive lingua ecology, transactional analysis, intent analysis, implicature analysis, analytical techniques of lingua cultural studies. 


\section{Materials and the results of the research}

The study of linguoecological problems of academic discourse requires a theoretical understanding of the role of emotions in the process of human cognitive activity. Positive emotions serve as a catalyst for the cognitive processes, while negative emotions can inhibit them. However, a harmonious development cannot be built on exclusively positive emotions as it can be an obstacle to the formation of adaptive abilities. In this regard, in our study the basic emotions by K. Izard were divided into three groups: emotions of active adaptation, or cognitively productive (joy, interest, surprise, anger); emotions of passive adaptation, or cognitively unproductive (sadness, disgust, fear, guilt, shame); and destructive (disdain).

This makes it evident that to create a favorable emotional background the teacher should develop the ability to manage the emotions of the audience: to create and maintain productive emotions and restrain unproductive ones. And since the position of the speaker / distributor of knowledge, depending on the situation, can be occupied by both the teacher and the student, it becomes obvious that the development of these skills is necessary for all participants in academic discourse. Therefore, the formation of relationships between speech partners in academic discourse should be based on compliance with the general communication code, or norms of academic communication.

Compliance with this code is reflected in the choice of environmentally friendly forms of speech interaction based on the formation of productive emotions. Based on this principle, all forms of speech interaction were divided into four groups: eco-friendly, nonecological, language therapy and destructive. Eco-friendly forms of speech interaction reflect compliance with the communication code. Non-ecological forms represent its violation and, as a rule, are the result of an insufficient level of emotional literacy of speech partners and can be neutralized with the help of language therapy forms of interaction. The latter type of forms of speech interaction is destructive, and unamenable to language therapy, since such forms destroy not only the relationship between partners, but in many cases their mental health.

The sustainability of discursive practices in the process of knowledge transfer, acquisition and exchange is in some way related to its productivity. In our previous research we showed that the emotiogenity (the potential to trigger an emotional response from the recipient) of discursive practices in the process of academic communication is related to its effectiveness through the phenomenon of information and cognitive needs, which is confirmed by the statistical-probabilistic model developed for the main genres of academic discourse [17]. This mathematical model also proves the possibility of forming a cognitive need in the process of academic communication where the main parameters are the right balance between the quality of the educational content and possible barriers to its assimilation, and positive general emotional environment. Yet another author's probabilistic model described in [18], a sociolinguistic method of Shared Emotions (SEM), makes it possible to carry out practical quantitative assessment of the emotiogenic potential of discursive units or to find out the preference of speech stimuli in terms of potential emotiogenic impact on the addressee. Using SEM we were able to identify a number of potentially non-ecological and destructive discourse elements that may be seen as obstacles to knowledge acquisition. Knowing what words and phrases may trigger negative emotional reaction in students, the teacher will be able to avoid many conflict situations in their professional activity.

The comparative discourse analysis also revealed a number of categorical emotional situations (CES) implemented within the following frames: adaptation to a speech partner, knowledge exchange, knowledge transfer, knowledge acquisition, class management, public assessment of knowledge, oral questioning [19]. 
The most environmentally dangerous and destructive CES should include CES of humiliation, revenge, and injustice, since they 1) are associated with clusters of escalated negative and simultaneously non-productive emotions (contempt, indignation, resentment, fear, and despair) characterized by a high emotional density, and 2) do not satisfy the natural human need for respect. Self-affirmation CES, which also represent a risk zone in the academic communication space, should be attributed to unavoidable situations, since this CES comes as a result of manifestation of natural psychological features of adolescence. The obtained conclusions are confirmed by the results of field studies. Statistical analysis of data obtained in the course of the field studies [20] shows that $52 \%$ of cases of communication ecology violations occur within CES of audience loss (explicit expression of intentions prevails), $21 \%$ - in the CES of self - affirmation, $3 \%$ - in in CES of revenge and $24 \%$ - in situations of manipulative communication [17, p. 189-211].

Categorical emotional situations can be provoked by both the teacher and the student [20], which means that not only the teacher should be able to avoid triggering negative emotions in students but also they have to manage with emotional strikes received from the student. One of the most productive linguistic tools in dealing with negative emotional situations provoked by students is reframing, a meta-model integrating the conflict discourse parts. As a type of speech interaction reframing expresses the desire to take the position of a partner and is based on the identification, evaluation, and processing of limiting beliefs. To eliminate student-triggered emotional situations a simple and explicit set of rules of speech conduct will also play an important role in building teacher-student relationships. Students should be taught to express themselves in the so-called "expected ways", as it is accepted in developed European and North American cultures.

Another conclusion the analysis allowed to draw was that using less formal register in communicating the educational content and phatic communication, and more formal register in challenging situations can be a helpful tool for class management. This principle, together with emotional restraint, is universal, and can make a great contribution to improving academic communication ecology in the Russian context.

Emotional restraint, though, cannot be supported constantly and in all situations. Based on the research findings, the best way to release emotions, especially in the context of Russian culture, is humour and self-irony [20].

Thus, according to the research findings, the module facilitating teacher-student communication and making it more productive should cover the following subject areas:

- the basics of the Russian academic language and the norms of academic communication;

- the basics of emotional language and potential emotiogenic effects of speech stimuli on the partner (emotional literacy);

- the use of the right language registers in different situations of academic communication;

- words and phrases to be avoided in teacher-student communication;

- the basics of reframing;

- ways of defense from emotional strikes;

- the anatomy of humour.

The research findings are consistent with literature (mostly European and American, which is explained by the innovativeness of this research in the Russian context):

1. While in an emotionally negative environment, a person usually tends to weaken their ability to produce healthy, emotionally positive statements: an unhealthy environment leads to an unhealthy perception of and attitude to the world, and this unhealthiness tends to further manifest itself on the physical level [21]. Thus, the problematic field of communicative ecology is not only the ethics and aesthetics of the discourse environment, but also the influence of the word on the mental and physical health of a person. Language 
usage can produce both toxic and therapeutic effects on the listener and in many cases people can be unaware of the potential emotiogenic effect of the words and phrases they say.

2. A brief comparative analysis of the English and Russian languages shows that the latter possesses a far richer potential of expressing emotions. Linguistic representation of emotions in the Russian language is very complicated. Choosing an emotional language tool is sometimes a difficult task even for a native speaker since this choice is not always clearly differentiated at the level of consciousness [22, p. 235], which leads to the conclusion that a teacher needs to have basic knowledge of the language, including emotional. The same conclusion was reached by Western researchers of academic communication $[23 ; 24$, etc.].

3. Besides emotional language, another aspect that should be taken into consideration in situations of teacher-student communication is academic language. Each culture has its own normality of speech behavior, which implies possession of a certain level of communication culture, compliance with the norms and rules of speech etiquette, along with awareness of the situational conditions of communication. Despite its prescriptive nature, the norms of interpersonal communication allow for some variation in the degree of strictness of their compliance [25]. In Western linguistics, the concept of academic discourse is interpreted as a way of thinking and using a language that exists and is operated in an educational institution. However, academic discourse is not only a tool that enables schools and universities to cope with the task of teaching students and carrying out scientific research. It also builds social roles and relationships that create teachers and students themselves (and ultimately - an average social discursive personality that determines the vector of development of this culture), supporting the existence of schools, universities, disciplines and knowledge itself. It shapes social reality, personal identity, and professional institutions. Academic discourse can be called the heart of an educational organization, a tool for cooperation, competition, and the creation of new knowledge. The academic space is inseparable from its discourses and cannot exist without them [26].

4. Lack of psychological readiness and underdeveloped practical skills of speech behavior in various categorical situations in the process of academic interaction are among the main difficulties that teachers encountered when implementing a new professional standard for teachers. According to a large-scale study in 2019, 79.08 \% of school teachers consider high requirements for narrowly focused knowledge and psychological training to be the main difficulty in implementing their professional activities [27].

5. In [28] the method of reframing is used to correct behavioral problems, including speech, in primary school. R. Thornberg reveals hidden signs of controlling, imposing a certain opinion discourse in the structure of a democratic school meeting which presupposes an open expression of students' opinions and ideas [29]. An experimental field study by R. Fonz and J. Salder focuses on the cognitive and emotional responses of high school children to applied educational strategies [30]. B. Griffith's book is an attempt to reframe all discursive practices of the educational space in order to find a common language for teachers and students [31].

6. Using less formal register when communicating educational content has been found as positively associated with learning outcomes [32;33].

7. Humor, according to foreign researchers (A. Cann, K. Holt, L.G. Calhoun, M.B. Wanzer, A.B. Frymier, T. Smith, etc.), is appropriate in all situations and major genres of academic discourse, because, unlike irony and sarcasm, humor does not have a personal focus and thus allows you to stay in the zone of polite communication. According to researchers who have summarized the experience of using humor in the audience $[34 ; 35]$, humor increases interest in learning, the level of knowledge and non-standard thinking, motivation, attendance, test results, reduces anxiety and stress levels when working with 
complex academic material, facilitates memorization, creates a positive social and emotional atmosphere in the audience and a general psychological connection between students and teachers. Western researchers insist that humor should be tied to the subject area of the transmitted knowledge, be understandable to the entire audience.

\section{Conclusions}

According to the research findings, the key to solving the identified systemic problems in academic discourse is to adjust the balance of the categories of self-respect - respect for the Other, which should be implemented at the stage of personal development, namely, at school. The environmental standards of communication that are laid down at this stage ultimately determine not only the models of social, academic and institutional interaction in a society, but also the intellectual potential of the nation.

Due to the scale of the problem under study, this paper is only able to present general guidelines that can set the direction of subsequent stages of scientific research. Further efforts, as it follows from the logic of the results obtained, should be directed at developing standards, creating educational texts, and then complementing pedagogical university programs with a special course or module aimed at developing the skills of emotional literacy and environmentally safe professional interaction of pre-service teachers. The listed subject areas of the course/module reflect only priority tasks, without exhausting all their diversity.

\section{References}

1. D.L. Altheide, An Ecology of Communication: Toward a Mapping of the Effective Environment. The Sociological Quarterly, 35 (4), 665-683 (1994)

2. S. Beder, Environmental Principles and Policies: An Interdisciplinary Introduction (Sydney, UNSW Press, 2006)

3. M. Foth, G. Hearn, Networked individualism of urban residents: Discovering the communicative ecology in inner-city apartment buildings. Information, Communication \& Society, 10 (5), 749-772 (2007)

4. G.Hearn, M. Foth, Communicative Ecologies: Editorial Preface. The Electronic Journal of Communication, 17 (1-2), (2007)

5. I.M. Dzyaloshinsky, Ecology of communications: the emergence of a new science. PR and Mass Media in Kazakhstan, 15, 27-37. (Almaty, 2018)

6. A.N. Logunov, Formation of safety skills in children of primary and secondary school age in the conditions of modern risks of socialization. Theory and practice of education in the modern world: proceedings of the IV international. scientific conf., 92-94 (Saint Petersburg: "Zanevskaya square", 2014)

7. A.S. Robotova, On the features of modern academic discourse. Higher education in Russia, 7, 9-19 (2011)

8. Z.N. Chekkueva, Teachers' verbal aggression as a destructive factor of teacher-students interpersonal interaction Society: sociology, psychology, pedagogy (2016), access mode: $\quad$ file:///C:/Users/ultrabook/Downloads/rechevaya-agressiya-pedagoga-kakdestruktivnyy-faktor-mezhlichnostnogo-vzaimodeystviya-v-sisteme-uchitel-uchenik.pdf

9. N.Ye. Lazunova, Reducing the culture of behavior of middle and senior school students and its impact on their academic performance (2017), access mode: https://multiurok.ru/files/stat-ia-snizhieniie-kul-tury-poviedieniia-shkol-ni.html 
10. V.V. Katunova, Reasons for Reduced Learning Motivation in Students with Attention Deficit Hyperactivity Disorder. Journal of Modern Foreign Psychology, 8 (2), 56-66 (2019)

11. Sh.F. Batyrshin, F. G. Fatkullina, Psychological and pedagogical competence of a university teacher. International Student Bulletin, 5, Part 3, 451-454 (2016)

12. E.A. Kazantseva, Social and psychological factors of pedagogical discourse disharmonization. Bulletin USPTU, 21 (3),116-123 (2017)

13. T.Z. Kozlova, Socio-psychological health of Russians depending on the age. Power, $\mathbf{5}$, 118-125 (2018)

14. R. Fojtik, Problems of Distance Education. International Journal of Information and Communication Technologies in Education, 7 (1), 14-23 (2018)

15. A.K. Suleymanova, F.G. Fatkullina, D.K. Saiakhova, E.R. Aitkulova, H.N. Ismagilova, Project-Based Learning as an Efficient Pedagogical Method to Develop Communicative Competences of the Present-Day School Students. "Editorial," Astra Salvensis, VI, 361370 (2018), access mode: https://astrasalva.files.wordpress.com/2018/07/astrasalvensis-vi-2018-special-issue.pdf

16. F.G. Fatkullina, Speech behavior of an elite language personality. Proceedings of the VI International scientific and practical conference dedicated to the 75th anniversary of Victory in the great Patriotic war, 151-157 (Ufa: the publ. house of Bashkir University, 2020)

17. E.A. Kazantseva, Statistical and probabilistic modeling of the process of generation of emotions in academic discourse. Bulletin of the Bashkir University, 24 (4), 1019-1024 (2019)

18. E.A. Kazantseva, Shared emotions method as a new research toolIn linguoecology of status-role communication, Bulletin of the Bashkir University, 25 (1), 1049-1055 (2020)

19. E.A. Kazantseva, Categorical emotional situations in Russian and English academic discourses World of science, culture and education, 1, 36-40 (2020).

20. E.A. Kazantseva, F.G. Fatkullina, E.K. Valiakhmetova, Lingvoecology of classroom discourse: student discourse practices and teacher perceptions. Advances in Social Science, Education and Humanities Research, V. 331, 324-328 (2019)

21. L.G. Aspinwall, R.G. Tedeschi, The value of positive psychology for health psychology: Progress and pitfalls in examining the relation of positive phenomena to health. Annals of behavorial medicine, 39 (1) 4-15 (2010)

22. S.V. Maslechkina, Expression of emotions in language and speech. Bulletin of the Bryansk state university, 3, 231-236 (2015)

23.23.E. Arnó, Knowledge about Language in English Language Courses for Future Language Professionals. Nordic Journal of English Studies, 5 (2009)

24. K.O. Bolarinwa, C.C. Okolocha, Influence of Classroom Interaction and Students' Attitude on Academic Achievement in Financial Accounting. Nigerian Journal of Business Education, 3 (2), 321-324 (2016)

25. L. Verbitskaya, Contemporary russian orthoepy and orthophony. Russian language abroad, 4, 14-19 (2011)

26. K. Hyland, Academic discourse, 171-184 (London, Continuum, 2011)

27. V.I. Toktarova, S.N. Fedorova, M.A. Mokoseeva, N.V. Kuzmin, E.E. Fliginskikh, Professional standard for teachers and federal stateeducational standards: comparative analysis. Vestnik of the mari state university, 13 (3), 391-400 (2019) 
28. L. Weiner, Challenging Deficit Thinking. Teaching to Student Strengths, 64 (1), $42-45$ (2006)

29. R.Thornberg, School democratic meetings: Pupil control discourse in disguise .Teaching and Teacher Education, 4 (26), 924-932 (2010)

30. R. Fawns, Jo. Salder, Managing students' learning in classrooms: Reframing classroom research. Research in Science Education, 26 (2), 205-217 (1996)

31. B. Griffith, Reframing Common Discourse (Sense Publishers, 2010)

32. K. Bain, What the best college teachers do (Cambridge, MA, Harvard University Press, 2004)

33. C.B. Cazden, Classroom discourse: The language of teaching and learning (Portsmouth, NH, Heinemann, 1988)

34. J. Busler, C. Kirk, W. Keeley, W. Buskist, What constitutes poor teaching? A preliminary inquiry into the misbehaviors of not-so-good instructors. Teaching of Psychology, 44 (4), 330-344 (2017)

35. J. Huss, S. Eastep, The attitudes of university faculty toward humor as a pedagogical tool: Can we take a joke? Journal of Inquiry \& Action in Education, 8 (1), 39-65 (2016) 